\title{
Metformin restores cisplatin cytotoxicity reduced by allantoin in CML in vitro
}

\author{
GRAZIELLE SILVA PAZ, GISELE CARDOSO DE AMORIM and JANAINA FERNANDES
}

NUMPEX-BIO, Duque de Caxias Campus, Federal University of Rio de Janeiro,

Duque de Caxias, Rio de Janeiro 25245-390, Brazil

Received February 21, 2021; Accepted July 14, 2021

DOI: $10.3892 /$ wasj.2021.116

\begin{abstract}
Tumor lysis syndrome (TLS) is a metabolic disorder that mainly affects patients with malignant hematological neoplasms, and its development is frequently related to uric acid accumulation (hyperuricemia). Rasburicase is a recombinant urate oxidase enzyme applied to treat and avoid TLS converting urate into allantoin, a compound easily eliminated by the kidneys. However, a recent study by the authors demonstrated in vitro that an elevated allantoin generation, which has been observed in oncological patients treated with rasburicase, reduced cisplatin cytotoxicity in a non-small cell lung cancer cell line (H460). Thus, it is necessary to determine the effects of the concomitant use of cisplatin and rasburicase for the treatment of patients with chronic myeloid leukemia (CML); due to the higher incidence of tumor lysis syndrome among patients with CML, it is necessary to search for adjuvant agents that can restore cisplatin cytotoxicity. Among adjuvant agents, metformin is of interest as it is effective, safe and has established pharmacological parameters. Thus, the present study evaluated the capacity of metformin to restore allantoin-reduced cisplatin cytotoxicity in a CML cell line (K562) in vitro. The cells were treated with metformin $(0.1,0.25,0.5,0.6025,2,2.5$ and $3 \mathrm{mM})$, cisplatin $(15,16.5$, 20, 30 and $33 \mu \mathrm{M})$, allantoin (100 and $200 \mu \mathrm{g} / \mathrm{ml})$, or their combinations for $48 \mathrm{~h}$. Cell viability, cell cycle, morphological analysis and nuclear magnetic resonance experiments were performed. The results revealed that allantoin reduced cisplatin cytotoxicity in the K562 cell line. Thus, metformin synergistically increased cisplatin-induced cell death and restored the cisplatin cytotoxicity that was reduced by allantoin.
\end{abstract}

Correspondence to: Dr Janaina Fernandes, NUMPEX-BIO, Duque de Caxias Campus, Federal University of Rio de Janeiro, Xerem Road 27, Duque de Caxias, Rio de Janeiro 25245-390, Brazil E-mail: janainaf@xerem.ufrj.br

Key words: chronic myeloid leukemia, tumor lysis syndrome, metformin, cisplatin, allantoin, adjuvant effect

\section{Introduction}

Chronic myeloid leukemia (CML) is a malignant hematological neoplasm responsible for $\sim 15 \%$ of all leukemia cases and occurs mainly in adults $>50$ years of age (1). In Brazil, the National Institute of Cancer predicts that an estimated 5.67 new cases of CML per 100,000 males and 4.56 new cases per 100,000 females will occur between 2020 and 2022. Thus, CML represents one of the ten most common types of cancer in Brazil (2).

CML is cytogenetically characterized by the presence of the Philadelphia chromosome, which is formed through a reciprocal translocation between the long arms of chromosomes 9 and 22 carrying the BCR-ABL gene (3). This gene encodes the BCR-ABL1 protein, which has high tyrosine kinase activity and leads to the activation of a number of pathways responsible for cancer development and progression (4).

The first-line treatment for CML is the use of tyrosine kinase inhibitors (TKIs). Although there are three generations of TKIs available, imatinib (a first-generation TKI) is commonly used due to its high efficiency. Resistance to imatinib is related to the growing development of the T315I mutation among patients with CML (5). As an alternative to imatinib, the third-generation TKI, ponatinib, can be employed due to its ability to counteract this mutation (6). However, researchers have recently demonstrated the occurrence of thrombosis cases related to the use of ponatinib (7). This has led to the adoption of a new therapeutic approach to evaluate the possible antileukemic effects of drugs already used to treat solid tumors (8). Furthermore, the efficiency of imatinib in removing malignant clones of CML is low and is considered a rare event, increasing the chances of relapse. There is an increase in the number of studies where cisplatin has been used in combination with imatinib in BCR-ABL ${ }^{+}$ CML cells (9). In addition, patients in blast crisis (BC; last phase of CML) are less responsive to TKIs, leading the search for therapeutic alternatives, such as the use of cisplatin in $\mathrm{BC}$ CML cells (10). In China, lobaplatin (cisplatin-derived drug) has been clinically used in the treatment of CML (11).

Cisplatin is a platinum-derived metallic coordination compound that is highly effective against several types of cancer (12). Following its administration and translocation to the intracellular environment through passive diffusion or by candidate transporters, such as copper transporter 
receptor 1 (CTR1) (13), cisplatin is activated through a series of aquation reactions on the cytosol that lead to the formation of DNA-protein and DNA-DNA intrastrand or interstrand crosslinks that cause DNA damage (14).

In patients undergoing chemotherapy, radiotherapy or immunotherapy, tumor lysis promotes the release of products of cellular degradation, such as xanthine, which is converted into urate through the purine degradation pathway (15). The high concentration of urate leads to the development of tumor lysis syndrome (TLS), which is common among patients with hematological malignancies, such as non-Hodgkin's lymphoma and leukemias (16).

TLS is a metabolic disorder that can affect several organs and can also lead to mortality. Among the main features of TLS, hyperuricemia (urate accumulation) may lead to renal failure. The evolutive loss of the urate oxidase gene from primates is responsible for urate accumulation in humans; the urate oxidase gene encodes uricase, an enzyme that converts urate in allantoin, a compound easily excreted by kidneys (17). Currently, rasburicase (Fasturtec ${ }^{\mathrm{TM}}$ ) is used to overcome TLS; rasburicase is a recombinant urate oxidase derived from Aspergillus flavus that converts urate into allantoin (18).

Allantoin, found in the leaf buds of Platanus orientalis, is a heterocyclic compound derived from the purine degradation pathway found in plants and animals (19). Due to its healing effects, allantoin has been used in a number of dermatological products, including products for wound care (20). Allantoin can also be found in small quantities in humans due to uric acid oxidation, which is indicative of oxidative stress (21).

A recent study by the authors revealed that allantoin reduced the effectiveness of cisplatin in a non-small cell lung cancer lineage (H460) as cancer patients that used rasburicase exhibited increased levels of allantoin (22).

Recently, several researchers have tested and obtained significant results with the use of cisplatin for the treatment of CML $(9,23,24)$. However, allantoin may interfere with cisplatin performance, which could lead to a misinterpretation of CML resistance and disease outcome.

Due to the need to treat TLS, the search for adjuvants that can function concomitantly with rasburicase has increased, and cisplatin is of great interest. Metformin stands out as a candidate for its effectiveness, safety, and other established pharmacological parameters.

Metformin is a biguanide drug derived from guanidine, the active substance of Galega officinalis, and is used as the first-line therapy for patients with type 2 diabetes mellitus (T2DM), due to its antihyperglycemic efficiency (25). Additionally, researchers have demonstrated the anti-neoplastic effects of metformin, either directly or indirectly, by acting in a number of tumorigenic pathways. The translocation of metformin to the intracellular environment is promoted by transporters, such as the plasma membrane monoamine transporter and organ-specific organic cation transporters 1 and 2 (26).

The majority of the effects of metformin are related to its effects on the mitochondria: Following the accumulation of metformin in the mitochondrial matrix due to the interaction between the positively-charged metformin and mitochondrial membrane potential, metformin inhibits complex I of the mitochondrial electron transport chain. This leads to an increased adenosine monophosphate (AMP)/adenosine triphosphate (ATP) ratio and, consequently, to the activation of AMP-activated protein kinase (AMPK), an important cellular energetic sensor that restores energetic cellular homeostasis disrupted by metformin (27). Thus, the aim of the present study was to evaluate the capacity of metformin as an adjuvant to restore cisplatin cytotoxicity in the presence of allantoin in a CML cell line.

\section{Materials and methods}

Cells and culture conditions. The CML cell line, K562, was maintained in Roswell Park Memorial Institute (RPMI-1640) medium (Sigma-Aldrich; Merck KGaA), supplemented with $10 \%$ fetal bovine serum (Gibco; Thermo Fisher Scientific, Inc.), $100 \mathrm{U}$ penicillin and $10 \mu \mathrm{g} / \mathrm{ml}$ streptomycin in cell culture bottles at $37^{\circ} \mathrm{C}$ in a $5 \% \mathrm{CO}_{2}$ humidified incubator. The cells were donated by Dr Vivian Rumjanek (Institute of Medical Biochemistry, Rio de Janeiro, Brazil) and sub-cultured every 2 days in $2 \times 10^{4}$ cells $/ \mathrm{ml}$. During experimentation, the cells were maintained in low glucose $(0.5 \mathrm{mM})$ RPMI-1640 supplemented as the culture medium. The cells tested negative for mycoplasma contamination.

Chemicals. Allantoin, dimethyl sulfoxide (DMSO), metformin hydrochloride, 3-(4,5-dimethylthiazole-2-yl)-2,5-diphenyltetrazolium bromide (MTT) and propidium iodide (PI) were purchased from Sigma-Aldrich; Merck KGaA. Cisplatin (Faudcispla, clinical solution) was purchased from Libbs Farmacêutica.

Allantoin was diluted in Dulbecco's modified Eagle's medium (DMEM) supplemented with $0.025 \%$ DMSO, which did not interfere with the function of cisplatin (data not shown). Allantoin was freshly diluted for each experiment.

Cell viability assay. To determine cell viability, $180 \mu \mathrm{l}$ of cell suspension was distributed in 96-well plates (1x104 cells/well) and pre-incubated with low glucose $(0.5 \mathrm{mM})$ availability for $2 \mathrm{~h}$ at $37^{\circ} \mathrm{C}$ and $5 \% \mathrm{CO}_{2}$ for culture stabilization. The drugs were dissolved in medium. Subsequently, the cells were treated with medium (control), metformin $(0.1,0.25,0.5,0.6025,2$, 2.5 and $3 \mathrm{mM})$, cisplatin $(15,20$ and $30 \mu \mathrm{M})$ and allantoin $(200 \mu \mathrm{g} / \mathrm{ml})$ for $48 \mathrm{~h}$. Following incubation for $48 \mathrm{~h}$ at $37^{\circ} \mathrm{C}$, MTT $(5 \mathrm{mg} / \mathrm{ml})$ was added to each well, and the cells were maintained for $4 \mathrm{~h}$ at $37^{\circ} \mathrm{C}$ in the dark. The plate was centrifuged at $1,008 \times \mathrm{g}$ for $3 \mathrm{~min}$ at $25^{\circ} \mathrm{C}$, and $150 \mu \mathrm{l}$ of DMSO were applied to dissolve the formazan crystals produced due to MTT reduction by viable cells. The optical density (OD) was measured at $570 \mathrm{~nm}$ using a microplate reader (SpectraMax ${ }^{\circledR}$ Multi-Mode Microplate Reader, Avantor ${ }^{\circledR}$ ), which was utilized to calculate the percentage of cell viability (OD of treated $\times 100 / O D$ of control). The results are presented as the mean \pm standard deviation (SD) percentage of cell viability of at least three different experiments performed in triplicate.

Calculation of combination index (CI). Following the cell viability assay, the half-maximal inhibitory concentration $\left(\mathrm{IC}_{50}\right)$ of metformin and cisplatin was utilized to evaluate the effect of drug combination by calculating the CI. The CI was calculated using the following equation: $\mathrm{CI}=(\mathrm{D}) \mathrm{com}_{1} /(\mathrm{D})_{1}+(\mathrm{D}) \mathrm{Com}_{2} /(\mathrm{D})_{2}$, where (D) $\operatorname{com}_{1}$ or (D)com ${ }_{2}$ represent the concentration of drug 1 

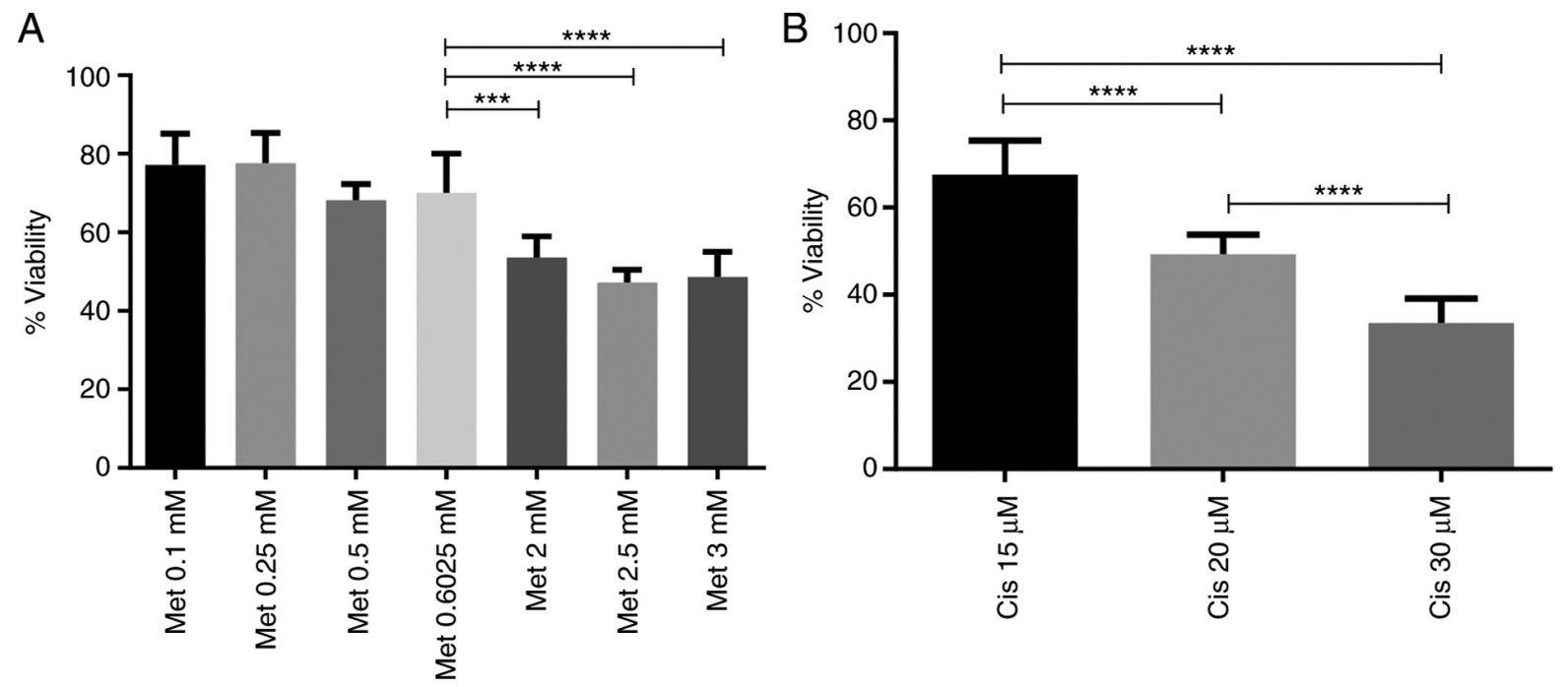

Figure 1. Metformin and cisplatin inhibit the viability of the CML cell line in a concentration-dependent manner. (A) Cells were incubated with metformin $(0.1,0.25,0.5,0.6025,2,2.5$ and $3 \mathrm{mM})$ under low glucose availability for $48 \mathrm{~h}$, and cell viability was assessed. (B) Cells were incubated with cisplatin (15, 20 and $30 \mu \mathrm{M}$ ) under low glucose availability for $48 \mathrm{~h}$, and cell viability was assessed. The columns represent the mean \pm SD of three experiments performed in triplicate. CML, chronic myeloid leukemia; Met, metformin; Cis, cisplatin. ${ }^{* * * *} \mathrm{P}=0.0003$ and ${ }^{* * * * *} \mathrm{P}=0.0000002$.

or 2 , respectively, that induce a $50 \%$ inhibition of cell viability in combination, and $(\mathrm{D})_{1}$ or $(\mathrm{D})_{2}$ represent the $\mathrm{IC}_{50}$ value from individual drug treatment. According to the CI value, it was possible to determine the type of combinatory effect: Additive $(\mathrm{CI}=1)$, synergistic $(\mathrm{CI}<1)$, or antagonistic $(\mathrm{CI}>1)$ effect.

Cell cycle analysis. The cell cycle was analyzed by flow cytometry. For this assay, $450 \mu 1$ of cell suspension were distributed in 24-well plates $\left(3 \times 10^{4}\right.$ cells/well) and pre-incubated for $2 \mathrm{~h}$ at $37^{\circ} \mathrm{C}$ and $5 \% \mathrm{CO}_{2}$ for culture stabilization. The cells were treated with medium (control), cisplatin (16.5 and $33 \mu \mathrm{M})$ with or without allantoin $(100 \mu \mathrm{g} / \mathrm{ml})$ for $48 \mathrm{~h}$. Subsequently, the cells were centrifuged at $21,952 \times \mathrm{g}$ for $20 \mathrm{sec}$ at $25^{\circ} \mathrm{C}$ and resuspended in a hypotonic fluorescence solution $(75 \mu \mathrm{M}$ propidium iodide and $0.1 \%$ Triton $\mathrm{X}-100$ in $0.1 \%$ sodium citrate buffer) for $1 \mathrm{~h}$ at $4^{\circ} \mathrm{C}$ in the dark, and the sub-G1, G1 and $\mathrm{G} 2$ peaks were obtained using a flow cytometer (BD Accuri ${ }^{\mathrm{TM}}$ C6, BD Biosciences). Data capture and analysis were performed using BD Accuri ${ }^{\mathrm{TM}}$ Analysis 1.0.264.21 Software (BD Biosciences). The results are presented as the mean \pm SD percentage of sub-G1, G1 and G2 cells of at least three different experiments performed in triplicate.

Morphological analysis. Bright field microscopy was used to evaluate changes in cell morphology following treatment. Briefly, $180 \mu \mathrm{l}$ of cells were seeded in 96 -well plates $\left(2 \times 10^{4}\right.$ cells/well) and maintained at $37^{\circ} \mathrm{C}$ and $5 \% \mathrm{CO}_{2}$ for $2 \mathrm{~h}$. The cells were treated with medium (control), metformin $(0.5 \mathrm{mM})$, cisplatin $(15 \mu \mathrm{M})$, allantoin $(200 \mu \mathrm{g} / \mathrm{ml})$, or their combinations for $48 \mathrm{~h}$. Following incubation for $48 \mathrm{~h}$ at $37^{\circ} \mathrm{C}$, two fields were photographed per well using a Leica DMI 6000 (x20 magnification) microscope. The experiment was performed in triplicate.

Nuclear magnetic resonance (NMR) spectroscopy. NMR is a technique used for the structural and functional characterization of molecules to analyze the interaction between proteins and drugs. To evaluate the possible drug interactions, metformin $(2.4 \mathrm{mM})$, allantoin $(2.4 \mathrm{mM})$, cisplatin $(40 \mu \mathrm{M})$, or their combinations were diluted in ultrapure $\mathrm{H}_{2} \mathrm{O}$ to a final volume of $1 \mathrm{ml}$ and incubated for $72 \mathrm{~h}$ at $37^{\circ} \mathrm{C}$. ${ }^{1} \mathrm{H}$ NMR spectra were acquired at $25^{\circ} \mathrm{C}$ on a Bruker Avance $400 \mathrm{MHz}$ spectrometer (Bruker Corporation); thereafter, spectra were processed and analyzed using TopSpin 2.0 (Bruker) software.

Statistical analysis. The results are presented as the mean \pm SD of at least three experiments performed in triplicate. The differences were analyzed using a one-way analysis of variance followed by Tukey's post hoc test. GraphPad Prism 6.0 software was used for the analyses, and $\mathrm{P}<0.05$ was considered to indicate a statistically significant difference.

\section{Results}

Metformin and cisplatin reduce the viability of the CML cell line in a concentration-dependent manner. Metformin and cisplatin have been demonstrated to exert anti-neoplastic effects in a number of types of cancer, such as in triple-negative breast cancer (TNBC) (28), meningioma (29) and esophageal cancer (30); however, little is known about their effects on the CML cell line, K562. These experiments were conducted under low-glucose availability, since it was already observed by other groups that under high glucose, metformin has a reducing effect $(30,31)$. As observed in Fig. 1A, the cells were treated with $0.1,0.25,0.5,0.6025$, 2, 2.5 and $3 \mathrm{mM}$ metformin for $48 \mathrm{~h}$. Metformin inhibited cell viability in a concentration-dependent manner, reaching $48.7 \pm 6.4 \%$ of viability at $3 \mathrm{mM}$. As with metformin, the cells were treated with 15,20 and $30 \mu \mathrm{M}$ cisplatin for $48 \mathrm{~h}$. Cisplatin also reduced viability in a concentration-dependent manner, reaching $33.5 \pm 5.5 \%$ at $30 \mu \mathrm{M}$. All comparisons were made with the untreated control (100\% of viability) (Fig. 1B). 
Table I. $\mathrm{IC}_{50}$ values of metformin and cisplatin.

\begin{tabular}{lc}
\hline Drug & $\mathrm{IC}_{50}$ value \\
\hline Metformin & $2.5 \mathrm{mM}$ \\
Cisplatin & $15 \mu \mathrm{M}$
\end{tabular}

Table II. CI calculation.

\begin{tabular}{lcccc}
\hline Drug & Dcom $(\mu \mathrm{M})$ & $\left.\mathrm{IC}_{50} \mu \mathrm{M}\right)$ & ${\text { Dcom } / \mathrm{IC}_{50}}$ & $\mathrm{CI}$ \\
\hline Cisplatin & 15 & 20 & 0.75 & 0.95 \\
Metformin & 500 & 2,500 & 0.2 & 0.95 \\
\hline
\end{tabular}

Calculation of the combination index $(\mathrm{CI})$ to the determination of the interaction type resulted of the combination between metformin and cisplatin. Dcom, concentration of the drug that in the combination inhibits $50 \%$ of cell viability; $\mathrm{IC}_{50}$, concentration of the drug that inhibits $50 \%$ of cell viability.

The results for metformin, demonstrated a reduction in cell viability across all concentrations; however, $0.5 \mathrm{mM}$ metformin, which reduced cell viability by $\sim 30 \%$, was selected for use in the following assays to examine the combined effect with cisplatin (Fig. 1A).

The results demonstrated that cisplatin reduced cell viability in a concentration-dependent manner (Fig. 1B). However, to assess the combined effect of metformin and cisplatin, the $15 \mu \mathrm{M}$ concentration of cisplatin, which reduced cell viability by $\sim 30 \%$, was selected to analyze the combined effect with metformin.

Metformin and cisplatin synergistically increase the death of the CML cell line. The cells were treated with 0.1, 0.25, 0.5 and $0.6025 \mathrm{mM}$ metformin, with or without $15 \mu \mathrm{M}$ cisplatin, for $48 \mathrm{~h}$. The results revealed an increased cytotoxic activity promoted by the combined use of both drugs when compared with the use of cisplatin alone (Fig. 2). The combination of $0.5 \mathrm{mM}$ metformin and $15 \mu \mathrm{M}$ cisplatin resulted in the highest inhibition of cell viability, by $\sim 50 \%$.

To determine the effects of the simultaneous use of metformin and cisplatin, the CI was calculated. To obtain the CI value, the $\mathrm{IC}_{50}$ of metformin $(0.5 \mathrm{mM})$ and cisplatin $(20 \mu \mathrm{M})$ was used (Table I). The CI value, which was 0.95 , demonstrated an increased cytotoxicity following the combined use of metformin and cisplatin, demonstrating a synergistic effect (Table II).

Allantoin reduces cisplatin cytotoxicity in the CML cell line. After demonstrating that metformin inhibited K562 cell viability and acted synergistically with cisplatin, the present study then evaluated whether allantoin reduced cytotoxicity induced by cisplatin. Thus, the cells were incubated with allantoin $(200 \mu \mathrm{g} / \mathrm{ml})$, cisplatin $(15 \mu \mathrm{M})$, or their combination for $48 \mathrm{~h}$, and cell viability was assessed. The results demonstrated that allantoin reduced $20 \%$ of cisplatin-induced cell death (Fig. 3).

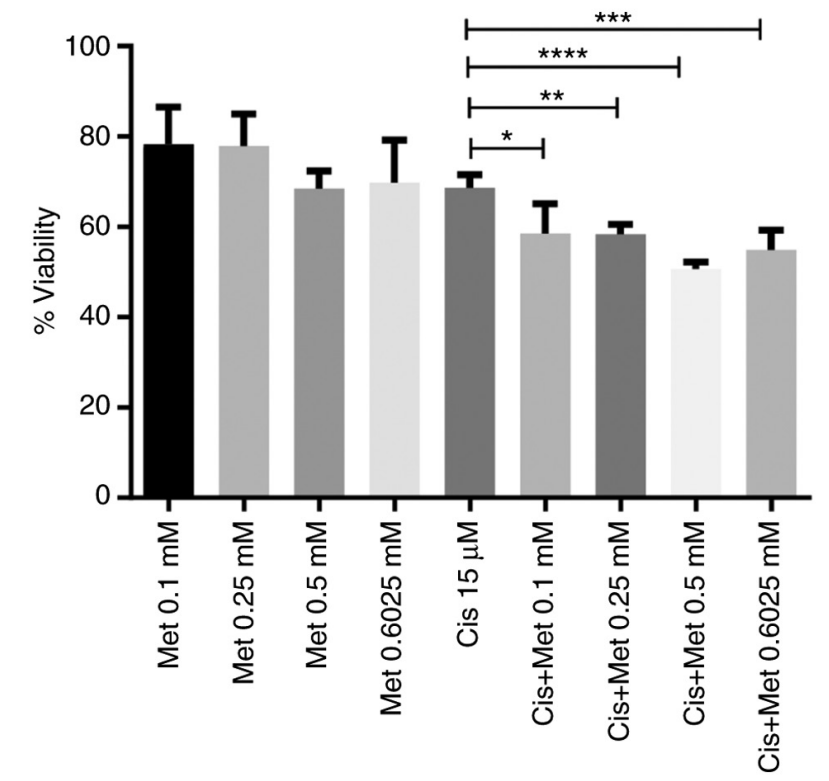

Figure 2. Metformin and cisplatin synergistically enhance the death of the CML cell line. Cells were incubated with metformin $(0.1,0.25$, 0.5 and $0.6025 \mathrm{mM})$, cisplatin $(15 \mu \mathrm{M})$, or their combination under low glucose availability for $48 \mathrm{~h}$, and cell viability was assessed. The columns represent the mean $\pm \mathrm{SD}$ of three experiments performed in triplicate ${ }^{*} \mathrm{P}=0.011,{ }^{* * *} \mathrm{P}=0.009,{ }^{* * *} \mathrm{P}=0.0001$ and ${ }^{* * * * *} \mathrm{P}=0.00000022$. CML, chronic myeloid leukemia; Met, metformin; Cis, cisplatin.

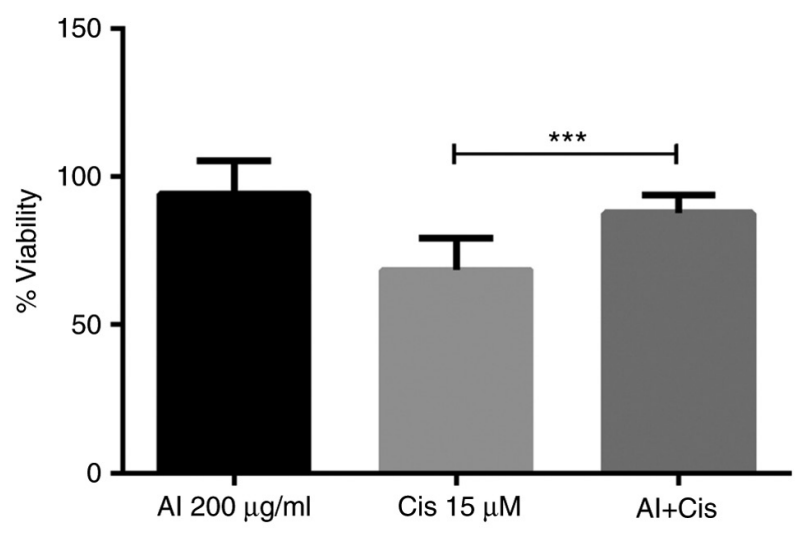

Figure 3. Allantoin reduces the cisplatin-induced death of the CML cell line. Cells were incubated with cisplatin $(15 \mu \mathrm{M})$, allantoin $(200 \mu \mathrm{g} / \mathrm{ml})$, or their combination under low glucose availability for $48 \mathrm{~h}$, and cell viability was assessed. The columns represent the mean $\pm \mathrm{SD}$ of three experiments performed in triplicate. ${ }^{* * * *} \mathrm{P}=0.0001$. CML, chronic myeloid leukemia; Met, metformin; Cis, cisplatin.

To examine the reduction of the effectiveness of cisplatin by allantoin, the cells were treated with $0.025 \%$ DMSO. To demonstrate that this concentration did not interfere with cisplatin activity, 16.5 and $33 \mu \mathrm{M}$ cisplatin, $100 \mu \mathrm{g} / \mathrm{ml}$ allantoin, or their combinations were incubated with the cells for $48 \mathrm{~h}$, and the cell cycle was analyzed (Fig. 4A). Allantoin reduced the percentage of sub-G1 cells (Fig. 4B) and enhanced the cell population in the G1 (Fig. 4C) and G2 phases of the cell cycle (Fig. 4D) induced by treatment with $33 \mu \mathrm{M}$ cisplatin, in addition to inducing cell cycle arrest in the G2 phase (Fig. 4D) following combined treatment with $16.5 \mu \mathrm{M}$ cisplatin, demonstrating that allantoin reduced the effectiveness of cisplatin in the CML cell line. 


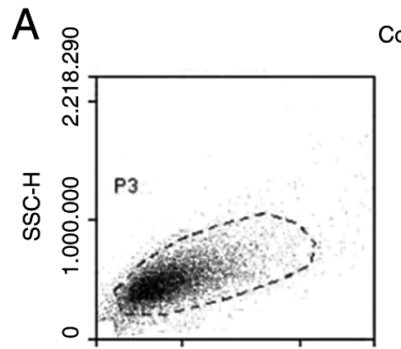

281.5061 .000 .0002 .000 .0002 .646 .153 FSC-H
Control

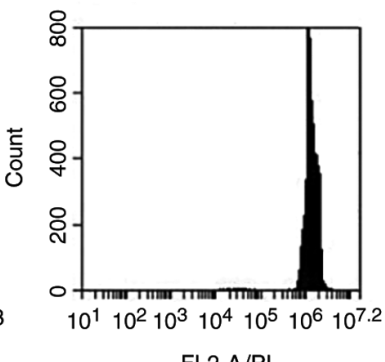

FL2-A/PI

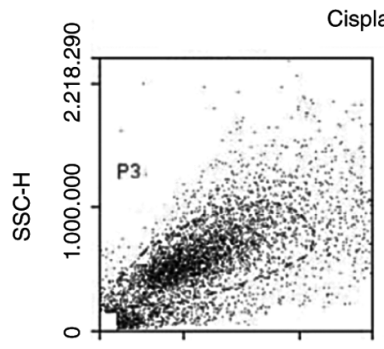

281.5061 .000 .0002 .000 .0002 .646 .153

FSC-H

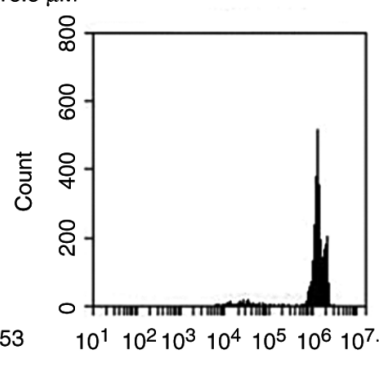

FL2-A/PI

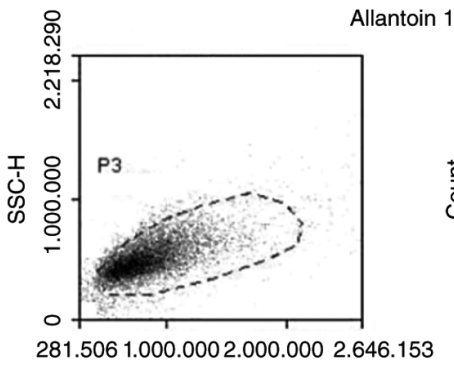

FSC-H

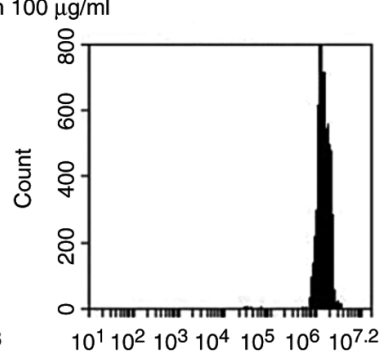

FL2-A/PI
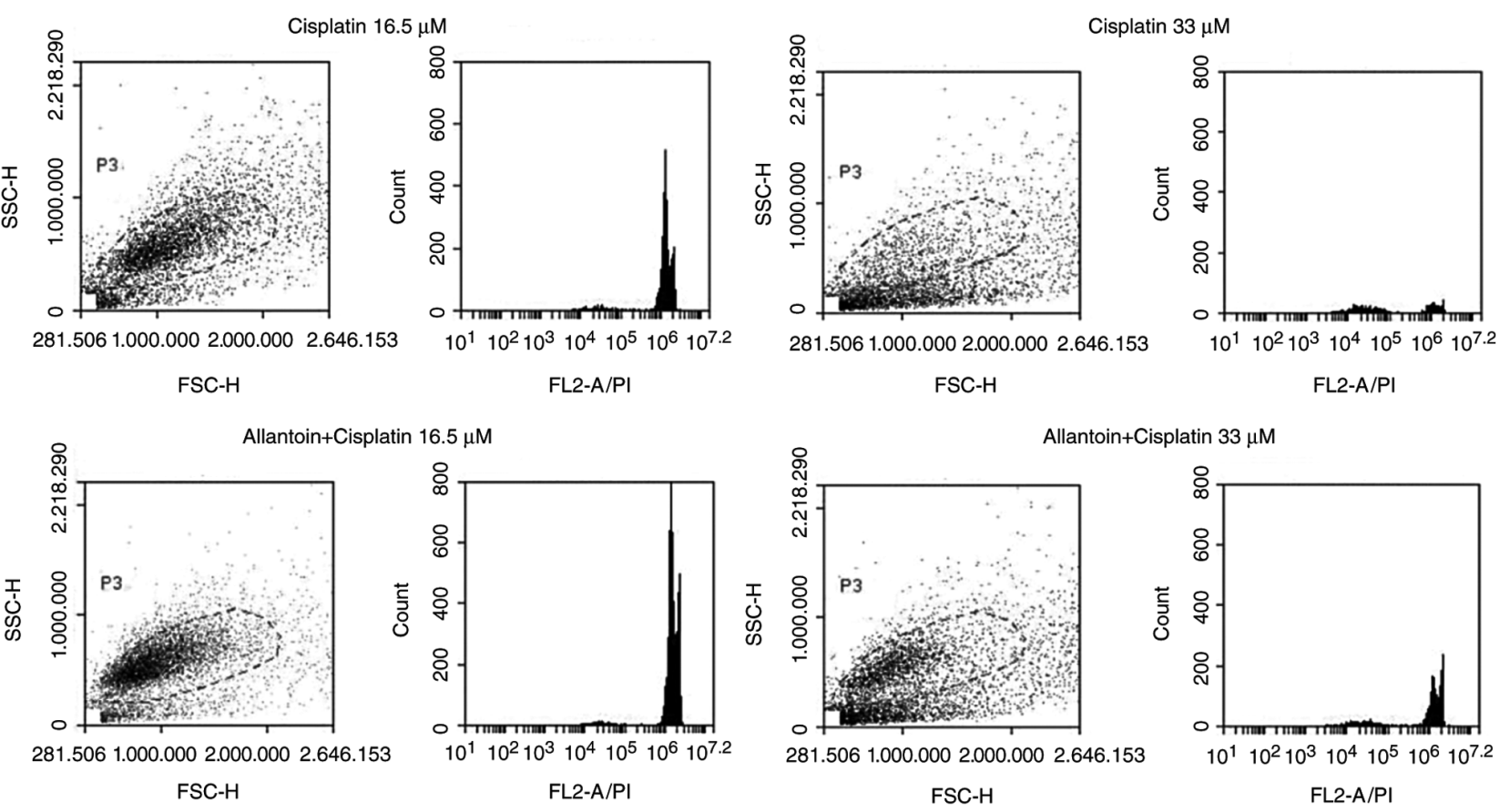

FL2-A/PI

FSC-H
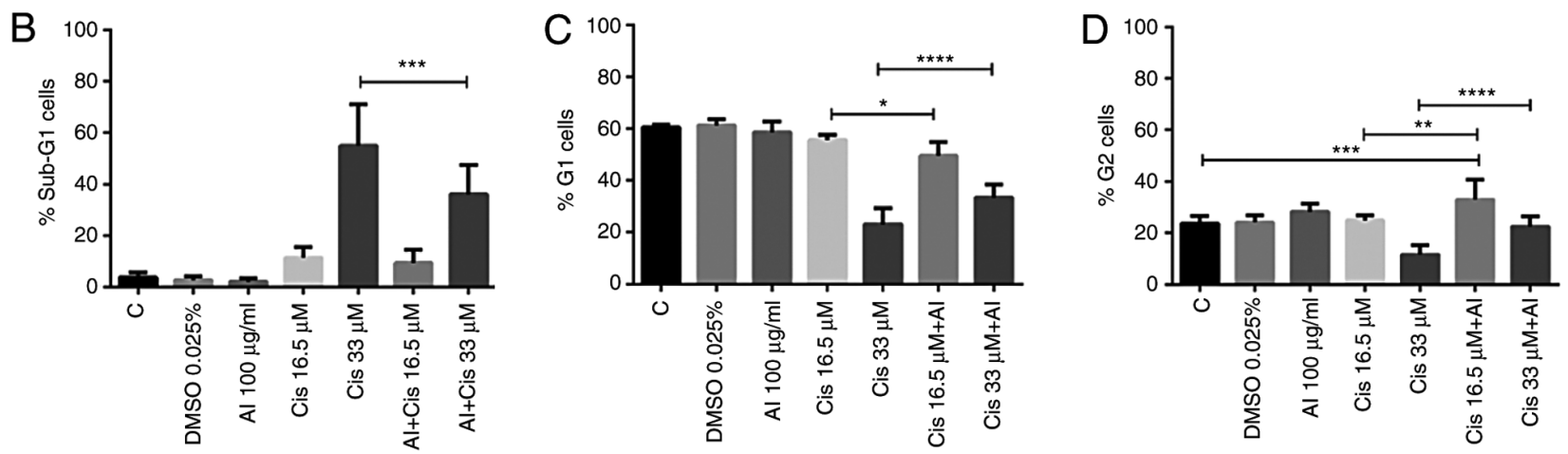

Figure 4. Allantoin reduces cisplatin-induced cell death in CML cells. Cells were incubated with medium (C) allantoin (100 $\mu \mathrm{g} / \mathrm{ml})$, cisplatin (16.5 and $33 \mu \mathrm{M})$, or their combination under low glucose availability for $48 \mathrm{~h}$, and the cell cycle were assessed. (A) Representative histograms of the data are present in panels B, $\mathrm{C}$ and D. (B) Percentage of sub-G1 cells. (C) Percentage of G1 cells. (D) Percentage of G2 cells. The columns represent the mean \pm SD of three experiments performed in triplicate. (B) ${ }^{* * *} \mathrm{P}=0.00011$; (C) ${ }^{*} \mathrm{P}=0.04517$ and ${ }^{* * * *} \mathrm{P}=0.00004$; (D) ${ }^{* *} \mathrm{P}=0.00219,{ }^{* * *} \mathrm{P}=0.00032$ and ${ }^{* * * *} \mathrm{P}=0.00001$. CML, chronic myeloid leukemia; Met, metformin; Cis, cisplatin.

Metformin reverses the reduced effectiveness of cisplatin induced by allantoin. As allantoin reduced the effectiveness of cisplatin in the CML cell line, and in search of adjuvant agents that may reverse this effect, the action of metformin as a possible adjuvant was analyzed. The cells were treated with $0.5 \mathrm{mM}$ metformin, $15 \mu \mathrm{M}$ cisplatin and $200 \mu \mathrm{g} / \mathrm{ml}$ allantoin, or their combinations for $48 \mathrm{~h}$, and cell viability was assessed. The results revealed that metformin reversed the allantoin-induced increase in the viability of the CML cell line treated with cisplatin (Fig. 5). This effect was also analyzed by examining cell morphological changes; for this assay, the cells were treated as aforementioned. The results revealed the formation of apoptotic bodies following metformin and cisplatin treatment and of these apoptotic bodies when combining these drugs, demonstrating the reduction in cisplatin-induced cell death following its combined use with allantoin, and the restoration of cell death following metformin treatment (Fig. 6). 


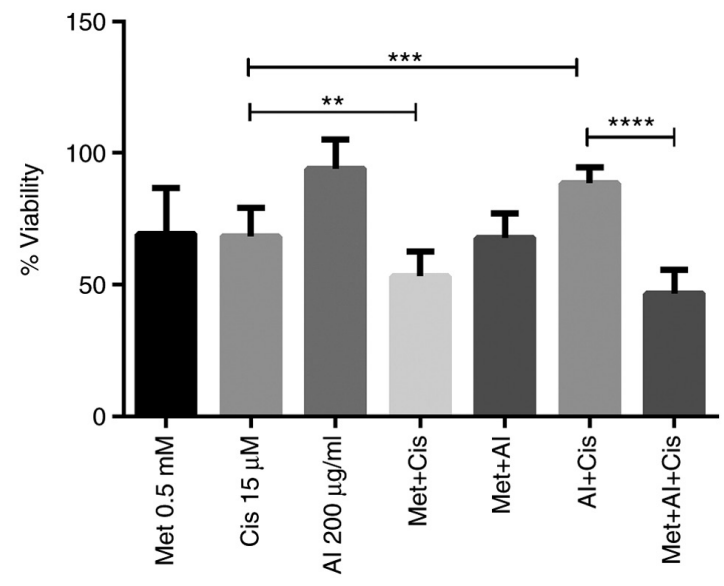

Figure 5. Metformin restores cisplatin viability inhibition reduced by allantoin in the CML cell line. Cells were incubated with metformin ( $0.5 \mathrm{mM})$, cisplatin $(15 \mu \mathrm{M})$, allantoin $(200 \mu \mathrm{g} / \mathrm{ml})$, or their combinations under low glucose availability for $48 \mathrm{~h}$, and cell viability was assessed. The columns represent the mean \pm SD of three experiments performed in triplicate. ${ }^{* *} \mathrm{P}=0.0061,{ }^{* * *} \mathrm{P}=0.0001$ and ${ }^{* * * * *} \mathrm{P}=0.00000001$. CML, chronic myeloid leukemia; Met, metformin; Cis, cisplatin; Al, allantoin.
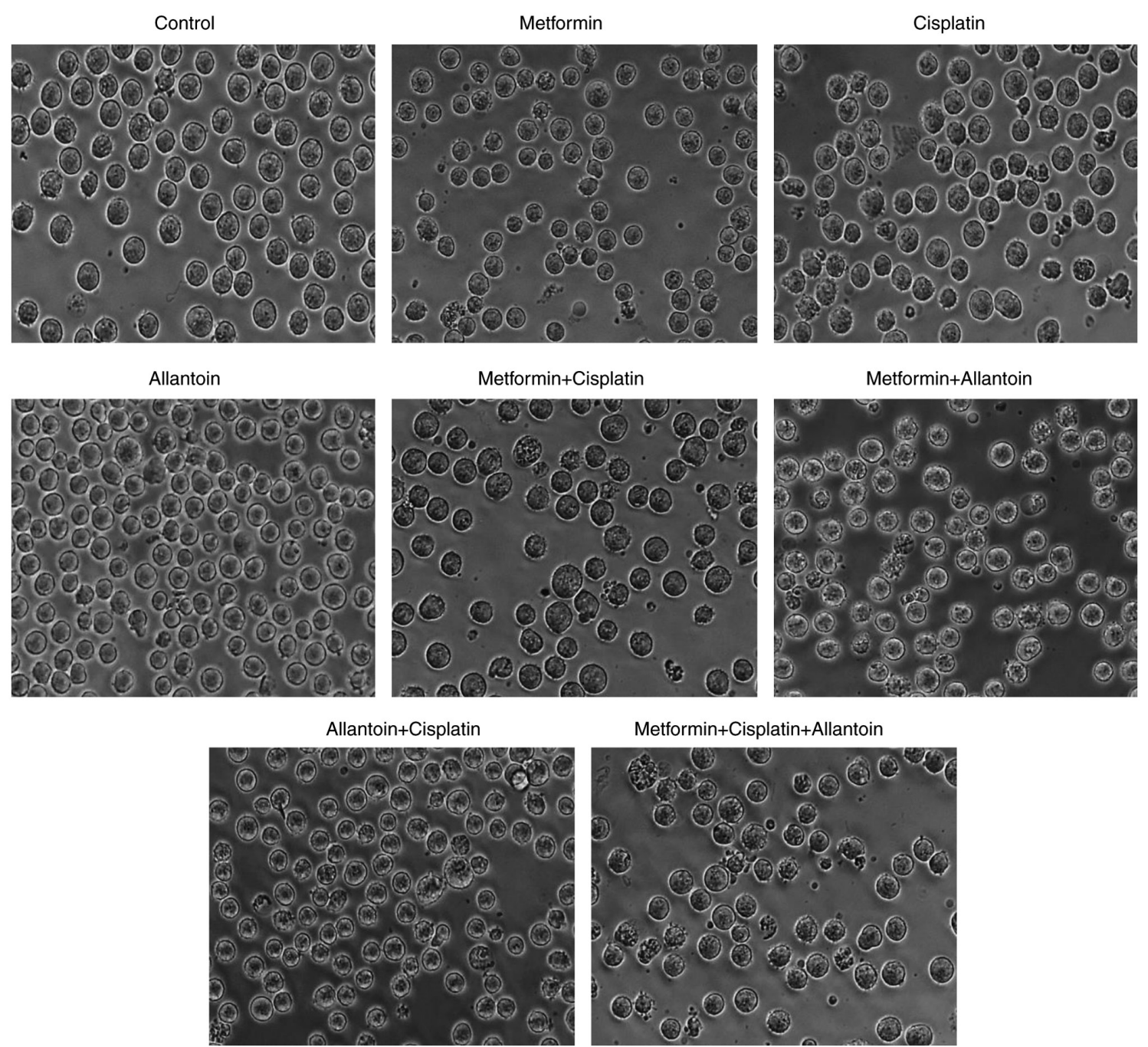

Figure 6. Metformin reverses the decreased effectiveness of cisplatin induced by allantoin and induces morphological changes in the CML cell line. Cells were incubated with medium (control) metformin $(0.5 \mathrm{mM})$, cisplatin $(15 \mu \mathrm{M})$, allantoin $(200 \mu \mathrm{g} / \mathrm{ml})$, or their combinations under low glucose availability for $48 \mathrm{~h}$, and cell morphology was photographed by bright field microscopy. CML, chronic myeloid leukemia.

Metformin possibly reverses the decreased effectiveness of cisplatin induced by allantoin through direct interaction. As demonstrated by the results, metformin was able to reverse decreased effectiveness of cisplatin induced by allantoin. 


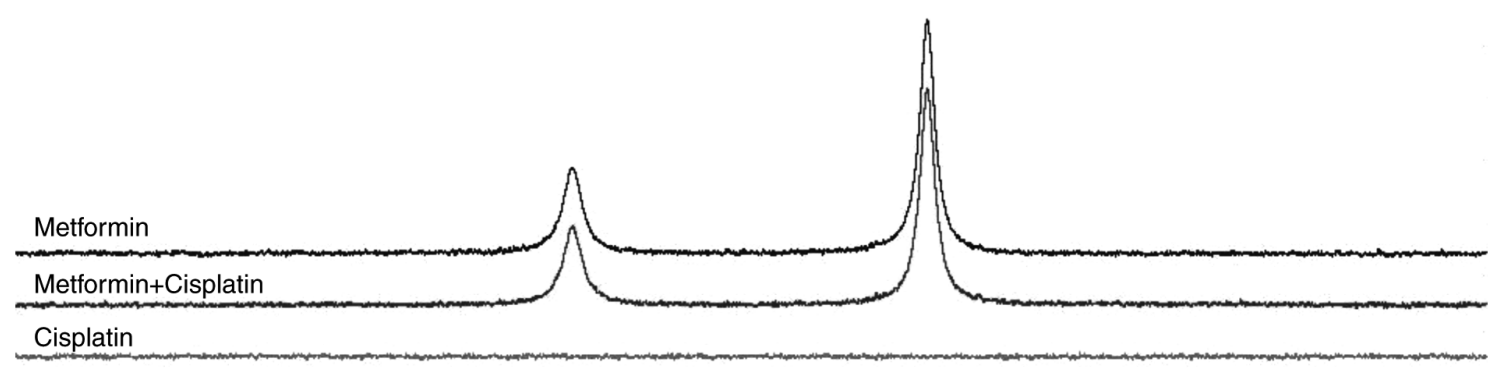

\begin{tabular}{|c|c|c|c|c|c|}
\hline 8.0 & & 7.0 & 6.5 & 6.0 & 5.5 \\
\hline
\end{tabular}

Figure 7. As per NMR, metformin and cisplatin do not interact. ${ }^{1} \mathrm{H}$ NMR spectra of metformin, cisplatin, and metformin + cisplatin.

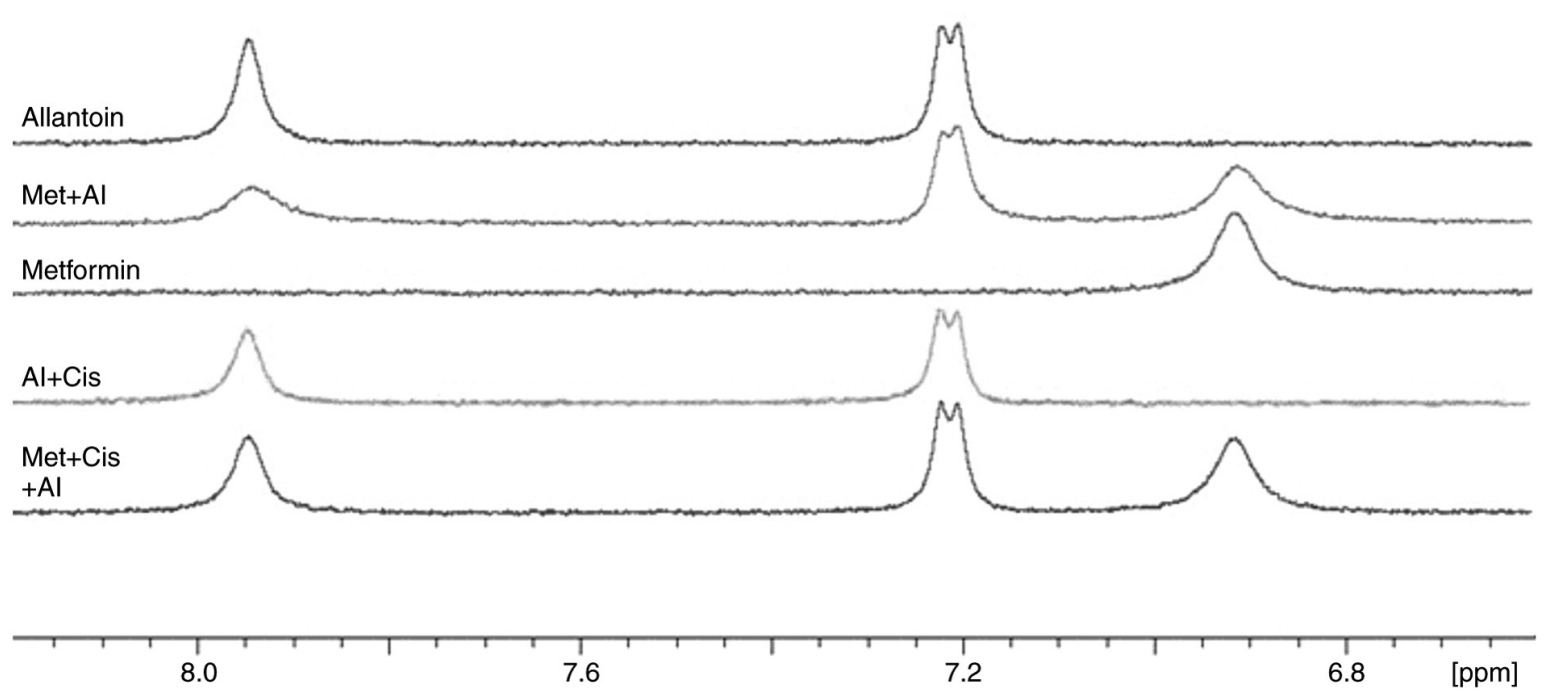

Figure 8. The possible interaction between metformin and allantoin. ${ }^{1} \mathrm{H}$ NMR spectra of allantoin, metformin + allantoin, metformin, allantoin + cisplatin, and metformin + cisplatin + allantoin.

However, the mechanisms through which metformin promoted this reversion were unclear. To investigate whether metformin interacts with allantoin or cisplatin to promote its activity, NMR spectroscopy was performed. As shown in Fig. 7, there was no chemical shift changes in the spectra of metformin and cisplatin when comparing the combined drugs and the drugs alone, indicating the absence of an interaction between metformin and cisplatin. As shown in Fig. 8, line broadening was observed for metformin and allantoin signals following their combined use, which may indicate an interaction. A recuperation of the metformin and allantoin original linewidths was also observed following the addition of cisplatin, which could indicate that cisplatin disrupted the metformin-allantoin interaction. Thus, metformin possibly reverses the decreased effectiveness of cisplatin induced by allantoin through its interaction with allantoin. However, other mechanisms also need to be investigated to elucidate the action of metformin in this phenomenon.

\section{Discussion}

CML is a malignant hematological neoplasm with an increasing worldwide occurrence, and despite advances in its treatment, a number of deaths due to CML still occur. Although TKI development has improved the disease outcome and patient survival, mutations have urged researchers to search for alternatives. Due to imatinib resistance, cisplatin is gaining interest as an alternative therapeutic approach for the treatment of CML due to its promising anti-leukemic effects in vitro $(9,10)$. Patients with hematological malignancies frequently develop TLS due to antitumoral chemotherapy with drugs, such as cisplatin that cause uric acid accumulation. To treat TLS and maintain the concomitant use of cisplatin, the recombinant urate oxidase, rasburicase, has been employed, which converts urate into allantoin. However, a recent study by the authors demonstrated that increased allantoin concentrations reduced the effectiveness of cisplatin in a non-small cell lung cancer cell line (H460) (22). Therefore, there is a need to search for adjuvant agents that may reverse this resistance; thus, the concomitant use of cisplatin and rasburicase to treat CML holds promise.

The present study demonstrated that all concentrations of metformin and cisplatin reduced cell viability when compared with the control (100\% of cell viability). MTT reduction occurs mainly in complex I of the mitochondrial electron transport chain (32) and depends on the mitochondria dehydrogenases, 
such as glycerol-3-phosphate dehydrogenase (33), which are inhibited by metformin action in the mitochondria $(34,35)$. Due to its mitochondrial effects, metformin opposes the Warburg effect, thereby reducing nicotinamide adenine dinucleotide phosphate (NADPH) production (36). Thus, mitochondrial impairment, glycerol-3-phosphate dehydrogenase inhibition and decreased NADPH production may explain the reduced cell viability caused by metformin. Due to complex I inhibition, metformin decreases nicotinamide adenine dinucleotide (NADH) oxidation, the mitochondrial membrane potential, and oxidative phosphorylation (36). Thus, the reduction in matrix metalloproteinase could result in apoptosis via the mitochondrial intrinsic pathway through the release of pro-apoptotic factors, such as cytochrome $c$ from the mitochondria into the cytosol, thereby causing caspase activation and cell death (37). Similar to metformin, cisplatin reduces mitochondrial activity through mitochondrial DNA adduct formation, inducing reactive oxygen species production and matrix metalloproteinase reduction (38). Therefore, cisplatin reduces glycolysis (39) and possibly reduces NADPH formation. Thus, the $\sim 30-70 \%$ reduction in cell viability by cisplatin may be related to NADPH reduction and mitochondrial impairment, resulting in decreased mitochondrial dehydrogenase activity.

The combination of metformin and cisplatin has demonstrated a therapeutic synergistic effect for a number of cancer types, such as in lung (40), esophageal (30) and gallbladder cancer (41) however, this combined effect was yet to be examined in a CML cell line, at least to the best of our knowledge. In the present study, the metformin-cisplatin combination promoted higher cytotoxicity than each drug in monotherapy, both under low $(0.5 \mathrm{mM})$ (Fig. 2). Through the CI calculation, it was determined that an increase in cytotoxicity induced by metformin-cisplatin combination therapy was synergistic (Table I). The mitochondrial activity and NADPH concentration contribute to the activity of dehydrogenase (42). Both metformin and cisplatin promote mitochondrial impairment and reduce glycolysis, leading to a significant reduction in NADPH availability $(43,44)$ that could reduce cell viability and the metformin-cisplatin synergistic effect.

A previous study by the authors demonstrated that allantoin reduced cisplatin effectiveness in the H460 cell line (22). Herein, it was determined that allantoin reduced cisplatin cytotoxicity in a CML cell line. It was also confirmed that allantoin reduced the effectiveness of cisplatin. Allantoin reduced the cell death induced by $33 \mu \mathrm{M}$ cisplatin and induced cell cycle arrest at the $\mathrm{G} 2$ phase when combined with $16.5 \mu \mathrm{M}$ cisplatin, thereby allowing the cells to repair their damaged DNA and survive. NMR spectroscopy performed by our group revealed an interaction between cisplatin and allantoin (22). Thus, due to this interaction, a low cisplatin concentration could exert cytotoxic effects, resulting in the reduced effectiveness of cisplatin in the leukemia cell line.

As it is important for oncological patients to maintain the concomitant use of cisplatin and rasburicase, the adjuvant effect of metformin to reverse cisplatin impairment was evaluated in the present study. Metformin reversed the decreased effectiveness of cisplatin induced by allantoin, as observed in the cell viability assay. It was also demonstrated that the reversion of cisplatin activity impairment by metformin induced morphological changes: A reduction in apoptotic bodies and cellular volume induced by cisplatin monotherapy was observed.

To assess the effect of metformin on allantoin activity, NMR spectroscopy was performed. The chemical shifts in metformin and cisplatin protons in the mixture were identical to those of each drug alone, indicating, at least by NMR, the absence of an interaction. Thus, the hypothesis that novel compound formation through the interaction between these drugs would have an effect that would overcome the effect of allantoin on cisplatin was discarded. Despite not observing an interaction between metformin and cisplatin, the possible interaction between metformin and allantoin could also indicate a mitochondria-independent reversal by metformin. As per the NMR spectra, the metformin-allantoin combination promoted line broadening, and the linewidths of metformin and allantoin proton signals were restored following the addition of cisplatin.

The shifts in the NMR signals could be explained by physical or chemical processes, such as binding, conformational changes, or solvent effects (e.g., pH or viscosity) (45). Thus, the observed line broadening following the metformin-allantoin combination could indicate an interaction. To discard solvent effects, the $\mathrm{pH}$ of each solution was verified and was unaltered.

Therefore, the restored metformin and allantoin linewidths following combined treatment with cisplatin may be related to a competition between metformin and cisplatin towards allantoin, thereby promoting a synergistic effect. Although metformin may reverse cisplatin impairment in a mitochondrial-independent manner, the mitochondrial effects of metformin may also be involved in this reversion. However, further studies are warranted to determine this phenomenon.

To the best of our knowledge, the present study is the first to demonstrate that: i) There was a synergistic effect between metformin and cisplatin in a CML cell line; ii) allantoin reduced the effectiveness of cisplatin in CML cells; iii) metformin reversed the allantoin-induced impairment in the effectiveness of cisplatin in CML cells; and iv) allantoin interacted with metformin. Thus, the present study highlights the importance of conducting in vivo and clinical studies on the use of metformin as an adjuvant for maintaining cisplatin and rasburicase concomitant use and understanding the mechanisms through which metformin exerts an adjuvant effect.

\section{Acknowledgements}

The authors would like to thank Dr Vivian Rumjanek, Professor and researcher at the Federal University of Rio de Janeiro (Rio de Janeiro, Brazil), for supplying the cells.

\section{Funding}

The present study was supported by the Research Support Foundation of Rio de Janeiro (FAPERJ; grant no. E-26/201.113/2019), the National Council for Scientific and Technological Development (CNPq), and the Coordination for the Improvement of Higher Education Personnel (CAPES). 


\section{Availability of data and materials}

The datasets used and/or analyzed during the current study are available from the corresponding author on reasonable request.

\section{Authors' contributions}

GSP and JF designed the study and wrote the manuscript. GCDA performed the NMR spectroscopy, assisted with the analysis of the results, and reviewed the manuscript. GSP performed all the other experiments and the analyzed data. GSP, GCDA and JF have read, approved the final version of this manuscript and confirmed the authenticity of all the raw data.

\section{Ethics approval and consent to participate}

Not applicable.

\section{Patient consent for publication}

Not applicable.

\section{Competing interests}

The authors declare that they have no competing interests.

\section{References}

1. American Society of Hematology (ASH): Blood cancers ASH, Washington, DC, 2020. http://www.hematology. org/Patients/Cancers/. Accessed October 10, 2020.

2. Paraguassu-Chaves CA, Filho AKDB, Almeida F, Dantas LRM, Neto JVF, dos Santos AM and Simões MDCR: Epidemiological, Sociodemographic And Clinical Profile of Men With Cancer in Rondônia, Brazilian Amazon. Int J Innov Educ Res 8: 374-408, 2020.

3. Apperley JF: Chronic myeloid leukaemia. Lancet 385: 1447-1459, 2015.

4. Goldman SC, Holcenberg JS, Finklestein JZ, Hutchinson R, Kreissman S, Johnson FL, Tou C, Harvey E, Morris E and Cairo MS: A randomized comparison between rasburicase and allopurinol in children with lymphoma or leukemia at high risk for tumor lysis. Blood 97: 2998-3003, 2001.

5. Bitencourt R, Zalcberg I and Louro ID: Imatinib resistance: A review of alternative inhibitors in chronic myeloid leukemia. Rev Bras Hematol Hemoter 33: 470-475, 2011.

6. Cortes JE, Kantarjian H, Shah NP, Bixby D, Mauro MJ, Flinn I, O'Hare T, Hu S, Narasimhan NI, Rivera VM, et al: Ponatinib in refractory Philadelphia chromosome-positive leukemias. N Engl J Med 367: 2075-2088, 2012.

7. Merkulova A, Mitchell SC, Stavrou EX, Forbes GL and Schmaier AH: Ponatinib treatment promotes arterial thrombosis and hyperactive platelets. Blood Adv 3: 2312-2316, 2019.

8. Westerweel PE, te Boekhorst PAW, Levin MD and Cornelissen JJ: New approaches and treatment combinations for the management of chronic myeloid Leukemia. Front Oncol 9: 665, 2019.

9. Skorta I, Oren M, Markwardt C, Gutekunst M, Aulitzky WE and van der Kuip H: Imatinib mesylate induces cisplatin hypersensitivity in Bcr-Abl+ cells by differential modulation of p53 transcriptional and proapoptotic activity. Cancer Res 69 9337-9345, 2009.

10. Xiao LY and Kan WM: p53 modulates the effect of ribosomal protein S6 kinase1 (S6K1) on cisplatin toxicity in chronic myeloid leukemia cells. Pharmacol Res 119: 443-462, 2017.

11. No authors listed: Lobaplatin: D 19466. Drugs R D 4: 369-372, 2003.

12. Dasari S, and Tchounwoun PB: Cisplatin in cancer therapy: Molecular mechanisms of action. Eur J Pharmacol 740: 364-378, 2014.
13. Kilari D, Guancial E and Kim ES: Role of copper transporters in platinum resistance. World J Clin Oncol 7: 106-113, 2016.

14. Siddik ZH: Cisplatin: Mode of cytotoxic action and molecular basis of resistance. Oncogene 22: 7265-7279, 2003.

15. Rampello E, Fricia T and Malaguarnera M: The management of tumor lysis syndrome. Nat Clin Pract Oncol 3: 438-447, 2006.

16. Belay Y, Yirdaw K and Enawgaw B: Tumor lysis syndrome in patients with hematological malignancies. J Oncol 2017: 9684909, 2017.

17. Howard SC, Jones DP and Pui CH: The tumor lysis syndrome. N Engl J Med 364: 1844-1854, 2011.

18. Alakel N, Middeke JM, Schetelig J and Bornhäuser M: Prevention and treatment of tumor lysis syndrome, and the efficacy and role of rasburicase. Onco Targets Ther 10: 597-605, 2017.

19. Becker LC, Bergfeld WF, Belsito DV, Klaassen CD, Marks JG Jr, Shank RC, Slaga TJ, Snyder PW and Alan Andersen F: Final report of the safety assessment of allantoin and its related complexes. Int J Toxicol 29 (Suppl 3): 84S-97S, 2010.

20. Araujo LU, Reis PG, Barbosa LC, Saude-Guimaraes DA, Grabe-Guimaraes A, Mosqueira VC, Carneiro CM and Silva-Barcellos NM: In vivo wound healing effects of Symphytum officinale L. leaves extract in different topical formulations. Pharmazie 67: 355-360, 2012

21. Kandar R, Stramova X, Drabkova P and Krenkova J: A monitoring of allantoin, uric acid, and malondialdehyde levels in plasma and erythrocytes after ten minutes of running activity. Physiol Res 63: 753-762, 2014.

22. Fernandes J, de Amorim GC, da Veiga TE, Cardoso J, Arruda AC, Arruda MSP and Castelo-Branco MTL: Allantoin reduces cell death induced by cisplatin: Possible implications for tumor lysis syndrome management. J Biol Inorg Chem 24: 547-562, 2019.

23. Xiao LY and Kan WM: p53 modulates the effect of ribosomal protein S6 kinase1 (S6K1) on cisplatin toxicity in chronic myeloid leukemia cells. Pharmacol Res 119: 443-462, 2017.

24. Xiao LY and Kan WM: Poly ADP-ribose polymerase inhibition suppresses cisplatin toxicity in chronic myeloid leukemia cells. Anticancer Drugs 28: 316-321, 2017.

25. Daugan M, Dufay Wojcicki A, d'Hayer B and Boudy V: Metformin: An anti-diabetic drug to fight cancer. Pharmacol Res 113 (Pt A): 675-685, 2016.

26. Liang $X$ and Giacomini KM: Transporters involved in metformin pharmacokinetics and treatment response. J Pharm Sci 106: 2245-2250, 2017.

27. Pernicova I and Korbonits M: Metformin-mode of action and clinical implications for diabetes and cancer. Nat Rev Endocrinol 10: 143-156, 2014.

28. Lee JO, Kang MJ, Byun WS, Kim SA, Seo IH, Han JA, Moon JW, Kim JH, Kim SJ, Lee EJ, et al: Metformin overcomes resistance to cisplatin in triple-negative breast cancer (TNBC) cells by targeting RAD51. Breast Cancer Res 21: 115, 2019.

29. Guo L, Cui J, Wang H, Medina R, Zhang S, Zhang X, Zhuang Z and Lin Y: Metformin enhances anti-cancer effects of cisplatin in meningioma through AMPK-mTOR signaling pathways. Mol Ther Oncolytics 20: 119-131, 2020.

30. Yu H, Bian X, Gu D and He X: Metformin synergistically enhances cisplatin-induced cytotoxicity in esophageal squamous cancer cells under glucose-deprivation conditions. Biomed Res Int 2016: 8678634, 2016.

31. Ma M, Ma C, Li P, Ma C, Ping F, Li W, Xu L, Zhang H, Sun Q and Li Y: Low glucose enhanced metformin's inhibitory effect on pancreatic cancer cells by suppressing glycolysis and inducing energy stress via up-regulation of miR-210-5p. Cell Cycle 19: 2168-2181, 2020.

32. Surin AM, Sharipov RR, Krasil'nikova IA, Boyarkin DP, Lisina OY, Gorbacheva LR, Avetisyan AV and Pinelis VG: Disruption of functional activity of mitochondria during MTT assay of viability of cultured neurons. Biochemistry (Mosc) 82: 737-749, 2017.

33. Lalle M, Camerini S, Cecchetti S, Finelli R, Sferra G, Müller J, Ricci G and Pozio E: The FAD-dependent glycerol-3-phosphate dehydrogenase of Giardia duodenalis: An unconventional enzyme that interacts with the g14-3-3 and it is a target of the antitumoral compound NDBHEX. Front Microbiol 6: 544, 2015.

34. Vial G, Detaille D and Guigas B: Role of mitochondria in the mechanism(s) of action of metformin. Front Endocrinol (Lausanne) 10: 294, 2019.

35. MacDonald MJ, Ansari IH, Longacre MJ and Stoker SW: If Metformin Inhibited the Mitochondrial Glycerol Phosphate Dehydrogenase It Might Not Benefit Diabetes. bioRxiv: doi: https://doi.org/10.1101/2020.03.28.013334. 
36. El-Mir MY, Nogueira V, Fontaine E, Avéret N, Rigoulet M and Leverve X: Dimethylbiguanide inhibits cell respiration via an indirect effect targeted on the respiratory chain complex I. J Biol Chem 275: 223-228, 2000.

37. Gao ZY, Liu Z, Bi MH, Zhang JJ, Han ZQ, Han X, Wang HY, Sun GP and Liu H: Metformin induces apoptosis via a mitochondria-mediated pathway in human breast cancer cells in vitro. Exp Ther Med 11: 1700-1706, 2016

38. Lomeli N, Di K, Czerniawski J, Guzowski JF and Bota DA: Cisplatin-induced mitochondrial dysfunction is associated with impaired cognitive function in rats. Free Radic Biol Med 102: 274-286, 2017.

39. Choi YM, Kim HK, Shim W, Anwar MA, Kwon JW, Kwon HK, Kim HJ, Jeong H, Kim HM, Hwang D, et al: Mechanism of cisplatin-induced cytotoxicity is correlated to impaired metabolism due to mitochondrial ROS generation. PLoS One 10: e0135083. 2015.

40. Teixeira SF, Guimarães Idos S, Madeira KP, Daltoé RD, Silva IV and Rangel LB: Metformin synergistically enhances antiproliferative effects of cisplatin and etoposide in NCI-H460 human lung cancer cells. J Bras Pneumol 39: 644-649, 2013 (In English, Portuguese).

41. Bi T, Zhu A, Yang X, Qiao H, Tang J, Liu Y and Lv R: Metformin synergistically enhances antitumor activity of cisplatin in gallbladder cancer via the PI3K/AKT/ERK pathway. Cytotechnology 70: 439-448. 2018.
42. Berridge MV and Tan AS: Characterization of the cellular reduction of 3-(4,5-dimethylthiazol-2-yl)-2,5-diphenyltetrazolium bromide (MTT): Subcellular localization, substrate dependence, and involvement of mitochondrial electron transport in MTT reduction. Arch Biochem Biophys 303: 474-482. 1993.

43. Thakur S, Daley B, Gaskins K, Vasko VV, Boufraqech M, Patel D, Sourbier C, Reece J, Cheng SY, Kebebew E, et al: Metformin targets mitochondrial glycerophosphate dehydrogenase to control rate of oxidative phosphorylation and growth of thyroid cancer in vitro and in vivo. Clin Cancer Res 24: 4030-4043, 2018.

44. Wang S, Xie J, Li J, Liu F, Wu X and Wang Z: Cisplatin suppresses the growth and proliferation of breast and cervical cancer cell lines by inhibiting integrin $\beta 5$-mediated glycolysis. Am J Cancer Res 6: 1108-1117, 2016.

45. Skinner AL and Laurence JS: High-field solution NMR spectroscopy as a tool for assessing protein interactions with small molecule ligands. J Pharm Sci 97: 4670-4695, 2008.

(i) (8) This work is licensed under a Creative Commons EY NO ND Attribution-NonCommercial-NoDerivatives 4.0 International (CC BY-NC-ND 4.0) License. 